\title{
Hemşirelik Öğrencilerinde Uyku Kalitesi ile Akademik Başarı Arasındaki İlişkinin İncelenmesi
}

\section{Investigation of the Relationship Between Sleep Quality and Academic Achievement in Nursing Students}

\author{
${ }^{1}$ Gizem EKENLER, ${ }^{2}$ Büşra ALTINEL
}

\author{
${ }^{1}$ Selçuk Üniversitesi Tip Fakültesi Hastanesi, Konya, Türkiye \\ ${ }^{2}$ Selçuk Üniversitesi Hemșirelik Fakültesi, Konya, Türkiye \\ Gizem Ekenler: https://orcid.org/0000-0002-2673-0090 \\ Büșra Altınel: https://orcid.org/0000-0002-9491-9012
}

\begin{abstract}
ÖZ
Amaç: $\mathrm{Bu}$ araştırmanın amacı; hemşirelik öğrencilerinde uyku kalitesi ile akademik başarı arasındaki ilişkiyi incelemektir.

Materyal ve Metot: Tanımlayıcı tipteki bu araştırma; Subat 2020- Haziran 2020 tarihleri arasında gercekleștirilmiştir. Araştırma; bir üniversitenin Hemşirelik Fakültesinde okuyan 280 öğrenci ile yürütülmüștür. Araştırma verileri Covid-19 salgını nedeniyle online formlar kullanılarak toplanmıştır. Araştırmada öğrencilerin özelliklerini değerlendirmeye yönelik bilgi formu ve Pittsburgh Uyku Kalitesi İndeksi (PUKİ) kullanılmıştır.

Bulgular: Arasstırmaya katılanların PUKİ puan ortalamas1 6,36 2,54 'tür. Öğrencilerin \%58,2'si PUKI' ye göre kötü uyku kalitesine sahiptir. Araștırmada sigara kullananların PUKİ puan ortalamas1 7,68 $\pm 2,56$; yatmadan önce kafeinli içecek tüketenlerin PUKİ puan ortalamas $7,16 \pm 2,59$; ders dinlerken uyuklayan öğrencilerin PUKİ puan ortalaması ise $6,55 \pm 2,63$ 'tür. Sigara kullanan, yatmadan önce kafeinli içecek tüketen ve ders dinlerken uyuklayan ögrencilerin PUKI'ye göre uyku kalitelerinin daha kötü olduğu tespit edilmistir. Arastırmaya katılanların PUKİ puan ortalamaları ile akademik puan ortalamalar arasında anlamlı bir ilișki bulunmuștur $(\mathrm{r}<0,20, \mathrm{p}<0,05)$.

Sonuç: Hemşirelik öğrencilerinin genel olarak uyku kalitelerinin kötü olduğu; uyku kalitesi PUKİ puanına göre kötü olanların akademik puan ortalamalarının daha düşük olduğu belirlenmiştir. Gelecekte profesyonel sağlık hizmetlerinin sunumunda yer alacak olan hemşirelik öğrencilerinin uyku kalitesinin önemi konusunda bilinçlendirilmesi için uygun danışmanlık hizmetleri verilebilir. Anahtar Kelimeler: Akademik başarı, hemşirelik, öğrenci, uyku kalitesi
\end{abstract}

\section{ABSTRACT}

Objective: The aim of this research is to examine the relationship between sleep quality and academic success in nursing students.

Materials and Methods: This descriptive research was held between February 2020-June 2020. The research was conducted with 280 students studying at the Nursing Faculty of a university. Research data were collected using online forms due to the Covid-19 outbreak. Information form and Pittsburgh Sleep Quality Index (PSQI) were used to evaluate the characteristics of the students in the study.

Results: The average PSQI score of the participants in the study is $6.36 \pm 2.54 .58 .2 \%$ of the students have poor sleep quality according to PSQI. The average PSQI score of smokers in the study was $7.68 \pm 2.56$; The average PSQI score of those who consumed caffeinated beverages before going to bed was $7.16 \pm 2.59$; The average PSQI score of students who doze while listening to the lesson is $6.55 \pm 2.63$. It has been determined that the quality of sleep of the students who smoke, consume caffeinated beverages before going to bed and sleep while listening to lessons are worse than the PSQI. A significant relationship was found between the PSQI mean scores of the participants and their academic score averages $(\mathrm{r}<0.20, \mathrm{p}<0.05)$.

Conclusion: Nursing students generally have poor sleep quality; It was determined that the academic score averages of those with poor sleep quality compared to their PSQI score were lower. Appropriate counseling services can be provided to raise awareness of the importance of sleep quality to nursing students, who will take part in the provision of professional health services in the future. Keywords: Academic success, nursing, sleep quality, student
Sorumlu Yazar / Corresponding Author:

Gizem Ekenler

Selçuk Üniversitesi Alaeddin Keykubat Yerleșkesi

Akademi Mahallesi Yeni İstanbul Caddesi No:313

42130-Selçuklu/Konya TÜRKIYE

Tel: +90544 5534218

E-mail: gizemekenler@gmail.com
Yayın Bilgisi / Article Info:

Gönderi Tarihi/ Received: 22/02/202

Kabul Tarihi/ Accepted: 02/10/2021

Online Yayın Tarihi/ Published: 01/12/2021

Atıf / Cited: Ekenler G ve Altınel B. Hemşirelik Öğrencilerinde Uyku Kalitesi ile Akademik Başarı Arasındaki İlişkinin İncelenmesi. Online Türk Sağlı Bilimleri Dergisi 2021;6(4):575-582. doi:10.26453/otjhs.883544 


\section{GíRiş}

Uyku, vücuttaki hücrelerin yenilenmesi, vücudun dinlenmesi, hafiza fonksiyonunun düzenlenerek öğrenmenin sağlanması ve yeni bir güne hazırlanma dönemini içeren bir süreçtir. ${ }^{1}$ Uyku kalitesi; bireylerin uykudan uyandiktan sonra kendilerini zinde ve yeni güne hazır hissetmeleri olarak tanımlanmaktadır. Uyku kalitesi, uyku ve uyanıklık fonksiyonlarının ayrıştırılmasıyla ilişkilidir. Uyku kalitesini; yaş, cinsiyet, çevresel faktörler, genetik faktörler, beslenme biçimi, yaşanılan yer, sosyal yaşam, ekonomik durum, fiziksel aktivite, genel sağlık durumu, stres, uyku zamanı alışkanlıkları ve ağrı gibi çeşitli faktörler etkileyebilmektedir. ${ }^{2}$

Üniversite dönemi, öğrencilerin birçoğu için ailelerinden ayrılmalarının yanı sıra alacakları kararlara, yapacakları seçimlere, karşılaşacakları sorunlara yönelik otonomilerinin arttığı büyük bir değişim dönemidir. Bu değişim uyku kalitesini olumsu şekilde etkileyebilmektedir. ${ }^{3}$ Uyku kalitesinin kötü olması da bilişsel fonksiyonlarda bozukluklara yol açarak akademik başarıyı olumsuz yönde etkileyebilmektedir. $^{4}$

Akademik başarı, öğrencilerin bilişsel davranışlarında önemli değişimlerin gerçekleştiğini gösteren bir ölçüttür. ${ }^{5}$ Öğrencinin fiziksel ve ruhsal iyilik hali, zihinsel kapasitesi, duyuşsal özellikleri, sosyoekonomik durumu, arkadaş grubu, ailesi, öğretim hizmetlerinin niteliği, üniversitenin imkanları, motivasyon ve meslek seçimi gibi birçok faktör akademik başarıyı etkilemektedir. ${ }^{6-8}$ Uyku da akademik başarıyı etkileyen faktörler arasındadır ve uykunun not ortalamasına en fazla etki eden faktör olduğu belirtilmektedir. ${ }^{8} \quad$ Mirghani ve ark. ${ }^{6}$ 'nın tıp öğrencileri üzerinde yapmış oldukları bir araştırmada; iyi uyku kalitesiyle akademik başarı arasında güçlü bir ilişki olduğu saptanmıştır. Yoldaş ${ }^{7}$ ’n üniversite öğrencilerine yönelik yapmış olduğu bir araştırmada kötü uyku kalitesiyle düşük akademik başarı arasında anlamlı bir ilişkinin olduğu belirtilmiştir. Uyku kalitesine yönelik yapılan araştırmalarda uyku kalitesinde en fazla değişiklik yaşayanlar üniversite öğrencileridir. ${ }^{4,9}$ Aysan ve ark. ${ }^{10}$ 'nın üniversite öğrencilerinde yapmış oldukları araştırmada; alkol alan, kafeinli içecek tüketen ve uyku süresi normalden az ve fazla olan öğrencilerin, uyku kalitelerinin kötü olduğu belirtilmiştir.

Sağlık alanındaki eğitimlerin yoğun olması öğrencilerin uyku zamanlarından fedakarlık etmelerine neden olabilmektedir. ${ }^{11}$ Uyku yoksunluğunun performans, konsantrasyon, dikkat ve hafiza bozukluklarına yol açtığı belirtilmiştir. ${ }^{6,12}$ Aldıkları eğitimler sonucunda topluma sağlı hizmeti verecek olan hemşirelik öğrencilerinin fiziksel ve ruhsal yönden tam bir iyilik halinde olmaları ve bunu sürdürebilmeleri önemlidir. ${ }^{10}$ _Öğrencilerin akademik başarıla- rının iyi olması, donanımlı mezunların yetiştirilmesinde ve meslek yaşamlarında nitelikli insan gücü olmalarında önemli rol oynamaktadır. ${ }^{13}$ Üniversite öğrencilerinde uyku kalitesi ve akademik başarı arasındaki ilişkiyi inceleyen araştırmalar ise sınırlı sayıdadır. Bu araştırma; hemşirelik öğrencilerinde, uyku kalitesinin akademik başarıya olan etkisine yönelik bir farkındalık oluşturmak ve hemşirelik ögrencilerinin uyku kalitesi ile akademik başarı arasındaki ilişkinin incelenmesi amacıyla planlanmış olup aşağıdaki sorulara yanıt aranmıştır:

1.Hemşirelik öğrencilerinin bazı temel özelliklerine göre PUKİ puanları farklılaşmakta mıdır?

2.Hemşirelik öğrencilerinin PUKİ puan ortalamaları nasildir?

3.Hemşirelik öğrencilerinin uyku kalitesi ile akademik başarı arasında bir ilişki var mıdır?

\section{MATERYAL VE METOT}

Araştırmanın Tipi ve Etik Yönü: Tanımlayıcı t p̈teki bu araştırma için Selçuk Üniversitesi Sağlık Bilimleri Fakültesi Girişimsel Olmayan Araştırmalar Etik Kurulu'ndan etik kurul (Tarih: 25.12.2019, karar no: 2019/14564) onayı ve Hemşirelik Fakültesi Dekanlığı'ndan da kurum izni alınmıştır. Pittsburgh Uyku Kalitesi İndeksi kullanım izni Türkçe geçerlilik ve güvenilirlik çalışmasını yapan Ağargün'den alınmıştır. Araştırma öncesinde öğrencilere araştırma hakkında bilgi verilmiş ve araştırmaya katılımın gönüllülük ilkesine bağlı olduğu belirtilmiştir.

Araştırmanın Yeri ve Zamanı: Bu araştırma Konya ilinde bulunan bir kamu üniversitesinin Hemşirelik Fakültesinde öğrenim gören öğrenciler üzerinde, Mart 2020-Mayıs 2020 tarihleri arasında yapılmıştır. Araştırmanın Evreni ve Örneklemi: Araştırmanın evrenini Konya ilinde bulunan bir kamu üniversitesinin Hemşirelik Fakültesi'nde öğrenim gören 827 (birinci sınıf 204, ikinci sınıf 215, üçüncü sınıf 209, dördüncü sınıf 199) öğrenci oluşturmuştur. Örnek büyüklüğü, evreni bilinen gruplarda örnek büyüklüğü ile hesaplanmış olup $\% 95$ güven aralığ $\% 5$ hata payı ile 263 öğrenci olarak belirlenmiştir. ${ }^{14}$ Örnek grubunun seçiminde öğrenciler sınıf düzeylerine göre tabakalandırılmıştır. Her bir sınıfta okuyan öğrenci sayısının birbirine yakın olması sebebiyle her sınıftan 70 öğrenci basit rastgele örnek seçim yöntemiyle seçilmiş ve 280 öğrenci örnek grubunu oluşturmuştur. Her sınıftan araştırmaya katılan tüm öğrencilere numara verilmiştir. Basit rastgele sayılar dizisi kullanılarak her sınıftan 70 öğrenci seçilmiştir. Araştırmaya internet erişimi olan öğrenciler dahil edilmiştir.

Veri Toplama Araçları: Araştırmada verṼer "Bilgi Formu" ve "Pittsburg Uyku Kalitesi İndeksi" kullanılarak elde edilmiştir.

Bilgi Formu: Araştırmacılar tarafindan IṼeratür 2, 6, 
8, 10,11, 15-17 incelenerek hazırlanan form; öğrencilerin sosyodemografik özelliklerine ilişkin 7, sağlık özelliklerine ilişkin 3, öğrencilerin uyku özelliklerine ilişkin 3 ve öğrencilerin 2019-2020 güz dönemi akademik ortalamasını değerlendirmeye yönelik 1 olmak üzere toplamda 14 sorudan oluşmuştur.

Pittsburgh Uyku Kalitesi İndeksi: Araştırmaya kat1lan öğrencilerin uyku kaliteleri, Pittsburgh Uyku Kalitesi İndeksi (PUKİ) ile değerlendirilmiştir. PUKİ, bir aylık süre içerisindeki uyku kalitesi ve uyku bozukluğunun tipi ve şiddeti konusunda bilgi veren bir özbildirim ölçeğidir. PUKİ 1989 yılında Buysse ve arkadaşları tarafından geliştirilerek yeterli iç tutarlılık, geçerlilik ve güvenirliğe uygun olduğu belirtilmiştir. ${ }^{18}$ Ölçeğin Türkçe geçerlik ve güvenirlik çalışması Ağargün ve arkadaşları tarafından yapılmış olup Türk toplumuna uygun olduğu belirtilmiştir. ${ }^{19}$ Ölçeğin orjinalinin Cronbach alfa iç tutarlılık katsayıs1 0,83 Türkçe uyarlamasının ise 0.80 olarak hesaplanmıştır. PUKİ toplamda 24 sorudan oluşmaktadır. Bu sorulardan 19 tanesi özbildirim sorusudur. Ölçekteki son 5 sorunun ise eş veya oda arkadaşı tarafindan yanitlanması gerekmektedir. $\mathrm{Bu} 5$ soru sadece klinik bilgi için kullanılmakta olup puanlamaya dahil edilmemektedir. Bu yüzden PUKİ'de 18 madde puanlamaya katılır. Sorular öznel uyku kalitesi, uyku latenti, uyku süresi, alışılmış uyku etkinliği, uyku bozukluğu, uyku ilacı kullanımı ve gündüz işlev bozukluğu olmak üzere yedi alt bileşenden oluşmaktadır. Her bir soru 0-3 arası puan verilerek değerlendirilmektedir. $\mathrm{Bu}$ yedi alt bileşene ait puanlar toplamı PUKİ'nin toplam puanını oluşturmaktadır. Toplam PUKİ puanı 0-21 arasında bir değere sahiptir. Toplam puan 5 ve 5 'den düşük olanların uyku kalitesi “iyi”; 5'den büyük olanların uyku kalitesi "kötü" olarak değerlendirilmektedir. ${ }^{19}$

Veri Toplanması: VerṼer Mart 2020-Mayıs 2020 tarihleri arasında tüm dünyayı etkisi altına alan Covid-19 salgını nedeniyle online anket formları kullanılarak toplanmıştır. Öğrencilere online anketlerin linki WhatsApp ${ }^{\circledR}$ sınıf grupları yoluyla ulaştırılmıştır. Araştırmacı tarafindan veri toplama araçları uygulanmadan önce öğrencilere araştırmanın konusuna ilişkin online olarak bilgi verilmiştir.

Veri Toplama Araçlarının Ön Uygulaması: Soru formunun anlaşılırlığını belirlemek amacıyla benzer bir gruptan 10 öğrenci üzerinde ön uygulama yapılmış ve bu öğrenciler örnekleme dahil edilmemişlerdir.

Verilerin Analizi: Araştırmanın ba ğımlı değ Ø̧ ken Ṽ akademik başarı düzeyidir, bağımsız değişkeni ise Pittsburg Uyku Kalitesi İndeksinden alınan puandır. Bağımlı ve bağımsız değişkenler arasındaki fark ve ilişkiyi incelemek için SPSS (Statistical Package for Social Sciences) 23 istatistik programı kullanılmıştır. Verilerin normal dağılıma uygunluğu “Tek Örneklem Kolmogorov Smirnov" analizi ile test edilmiştir. Normal dağılıma uyan iki gruplu değişkenlerin skorlarını karşılaştırmada parametrik testlerden Independent Samples T Testi ve üç ya da daha fazla gruplu değişkenlerin skorlarını karşılaştırmada ise Tek Yönlü Varyans Analizi (ANOVA) testi kullanılmıştır. Akademik puan ortalaması ve Pittsburgh Uyku Kalitesi İndeksi puan ortalaması arasındaki ilişkiyi incelemede Pearson Korelasyon Analizi kullanılmıştır. İstatistiksel anlamlılık düzeyi $\mathrm{p}<0,05$ olarak kabul edilmiştir.

Araştırmanın Sınırlılıkları: Araştırmaya sadece Selçuk Üniversitesi Hemşirelik Fakültesinde lisans öğrenimi gören öğrencilerin alınması araştırmanın sınırlılıkları arasında yer almaktadır.

\section{BULGULAR}

Tablo 1'de araştırmaya katılan öğrencilerin temel özellikleri verilmiştir. Araştırmaya katılan öğrencilerin yaş ortalamaları $20,59 \pm 1,54$ olup, \%88,2'si kadındır. Araştırmaya katılanların \%99,6'sı bekar ve \% 86,4 'ünün ekonomik durum alg1s1 orta düzeydedir. Öğrencilerin \%47,1'i ailesiyle evde, \%38,2'si devlet yurdunda ikamet etmektedir. Araştırma kapsamına alınan öğrencilerin \%3,6'sı part time bir işte çalışmakta ve \%10,7'sinin bir kronik hastalık bulunmaktadır. Öğrencilerin \%8,9'u sigara, \%2,9'u alkol kullanmaktadır. Araştırma kapsamına alınan öğrencilerin $\% 97,1$ 'i uyumadan önce internet kullanmakta, \% 37,5'i yatmadan önce kafeinli içecek tüketmekte ve $\% 75,7$ 'si ders dinlerken uyuklamakta olduğu tespit edilmiştir.

Tablo 2'de araştırmaya katılan öğrencilerin temel özellikleri ile PUKİ puan ortalaması karşılaştırılması verilmiştir. Öğrencilerin PUKİ uyku kalitesi toplam puan ortalaması $6,36 \pm 2,54$ 'tür. PUKİ puan ortalaması 5 'ten büyük olan öğrencilerin oranı \%58,2'dir. Araştırma kapsamına alınan öğrencilerin sigara kullanma durumu, yatmadan önce kafeinli içecek tüketme durumu ve ders dinlerken uyuklama durumu ile PUKİ puan ortalamaları arasında istatistiksel açıdan anlamlı bir fark bulunmuştur $(\mathrm{p}<0,05)$.

Tablo 3' te Araştırmaya katılanların PUKİ puan ortalamaları ile akademik puan ortalamalarının karş1laştırılmasına yer verilmiştir. Katılımcıların akademik ortalamaları ile PUKİ puan ortalamaları arasında istatistiksel açıdan çok zayıf negatif bir ilişki tespit edilmiştir $(r<0,20 ; p<0,05)$. 
Tablo 1. Öğr enciler in temel özelliklerinin dağılımı.

\begin{tabular}{|c|c|c|c|c|c|}
\hline \multicolumn{3}{|l|}{ Tanıtıcı Özellikler } & \multirow[t]{2}{*}{ Tanıtıcı Özellikler } & \multirow[t]{2}{*}{ Sayı (n) } & \multirow[t]{2}{*}{$\begin{array}{l}\text { Yüzde } \\
(\%)\end{array}$} \\
\hline Yaş & \multicolumn{2}{|c|}{$($ ort $\pm \mathrm{sS}=20,59 \pm 1,54)$} & & & \\
\hline & \multirow{2}{*}{ Sayı (n) } & \multirow{2}{*}{$\begin{array}{l}\text { Yüzde } \\
\text { (\%) }\end{array}$} & \multicolumn{3}{|c|}{ Part-time işte çalışma durumu } \\
\hline & & & Çalışan & 10 & 3,6 \\
\hline \multicolumn{3}{|l|}{ Cinsiyet } & Çalışmayan & 270 & 96,4 \\
\hline Kadın & 247 & 88,2 & \multicolumn{3}{|c|}{ Herhangi bir kronik hastalığı olma durumu } \\
\hline Erkek & 33 & 11,8 & Evet, var & 30 & 10,7 \\
\hline \multicolumn{3}{|l|}{ Medeni Durum } & Hayır, yok & 250 & 89,3 \\
\hline Bekar & 279 & 99,6 & \multicolumn{3}{|l|}{ Sigara kullanma durumu } \\
\hline Evli & 1 & 0.4 & Evet, kullanıyor & 25 & 8,9 \\
\hline Sinıf & & & Hayır, kullanmıyor & 255 & 91,1 \\
\hline 1.Sinif & 70 & 25 & \multicolumn{3}{|l|}{ Alkol kullanma durumu } \\
\hline 2.S1n1f & $\frac{10}{70}$ & $\frac{25}{25}$ & Evet, kullanıyor & 8 & 2,9 \\
\hline 3.Sinıf & 70 & $\frac{25}{25}$ & Hayır, kullanmıyor & 272 & 97,1 \\
\hline 4.Sinif & 70 & $\frac{25}{25}$ & \multicolumn{3}{|c|}{ Uyumadan önce internet kullanma durumu } \\
\hline \multicolumn{3}{|l|}{ Ekonomik Durum } & Evet, kullanıyor & 272 & 97,1 \\
\hline İyi & 25 & 8,9 & Hayır, kullanmıyor & 8 & 2,9 \\
\hline Orta & 242 & 86,4 & \multicolumn{3}{|c|}{ Yatmadan önce kafeinli içecek tüketimi durumu } \\
\hline Kötü & 13 & 4,6 & Evet, tüketiyor & 105 & 37,5 \\
\hline \multicolumn{3}{|l|}{ İkametgâh ettiği yer } & Hayır, tüketmiyor & 175 & 62,5 \\
\hline Ailemle evde & 132 & 47,1 & \multicolumn{3}{|c|}{ Ders dinlerken uyuklama durumu } \\
\hline Devlet yurdu & 107 & 38,2 & Evet, uyukluyor & 212 & 75,7 \\
\hline Özel yurt & 25 & 8,9 & \multirow{3}{*}{ Hayır, uyuklamıyor } & 68 & 24,3 \\
\hline Arkadaşımla evde & 12 & 4,3 & & & \\
\hline Tek başina evde & 4 & 1,4 & & & \\
\hline
\end{tabular}

Tablo 2. Öğrenciler in temel özellikleri ile PUKİ puan ortalamalarının karşılaştırılması.

\begin{tabular}{|c|c|c|c|}
\hline Tanıtıcı Özellikler & $\mathbf{n}$ & $\begin{array}{l}\text { PUKİ Puan } \\
\text { Ortalaması }\end{array}$ & $\mathbf{p}$ \\
\hline \multicolumn{4}{|l|}{ Cinsiyet } \\
\hline Kadın & 247 & $6,38 \pm 2,56$ & \multirow{2}{*}{$\begin{array}{l}\mathrm{t}=0,502 \\
\mathrm{p}=0,416\end{array}$} \\
\hline Erkek & 33 & $6,15 \pm 2,37$ & \\
\hline \multicolumn{4}{|l|}{ Sinıf } \\
\hline 1.Sinif & 70 & $6,57 \pm 2,39$ & \multirow{4}{*}{$\begin{array}{l}F=0,718 \\
p=0,542\end{array}$} \\
\hline 2.Sinif & 70 & $6,01 \pm 2,28$ & \\
\hline 3.Sinif & 70 & $6,54 \pm 2,65$ & \\
\hline 4.Sinif & 70 & $6,31 \pm 2,83$ & \\
\hline \multicolumn{4}{|l|}{ Ekonomik Durum } \\
\hline İyi & 25 & $5,84 \pm 2,79$ & \multirow{3}{*}{$\begin{array}{l}\mathrm{F}=1,287 \\
\mathrm{p}=0,278\end{array}$} \\
\hline Orta & 242 & $6,36 \pm 2,54$ & \\
\hline Kötü & 13 & $7,23 \pm 2,54$ & \\
\hline
\end{tabular}

PUKİ: Pittsburgh Uyku Kalitesi İndeksi .

\section{TARTIŞMA VE SONUÇ}

Hemşirelik öğrencilerinde uyku kalitesi ile akademik başarı arasındaki ilişkinin incelenmesine yönelik yapılan bu araştırmada öğrencilerin büyük bir kısmının uyku kalitelerinin kötü olduğu belirlenmiştir. Ülkemizde hemşirelik ve ebelik öğrencilerinde uyku kalitesine yönelik yapılan bir araştırmada; uyku kalitesi toplam puan ortalaması $6,52 \pm 2,81$ 'dır ve uyku kalitesi puan ortalaması 5 'ten büyük olan öğrencilerin oran $\% 62,75{ }^{\prime}$ tir. $^{20}$ Hindistan'da hemşirelik öğrencilerinin uyku kalitesine yönelik yapılan bir araştırmada öğrencilerin \%82,42'sinin kötü uyku kalitesine sahip olduğu tespit edilmiştir. ${ }^{9}$ Yapılan bu araş- tırma da literatüre benzer özellik göstermekte olup uyku kalitesi kötü olan öğrencilerin oranı yarıdan fazladır. Araştırmada katılımcıların cinsiyet, öğrenim gördükleri sınıf, ekonomik durum algısı, ikamet ettiği yer, part time çalışma durumu, kronik hastal1ğa sahip olma durumu özelliklerine göre uyku kalitesi incelendiğinde istatistiksel açıdan anlamlı bir fark bulunmamıştır ( $>00,05$; Tablo 2). Uyku kalitesi üzerine yapılan araştırmalarda da cinsiyet ve uyku kalitesi arasındaki ilişki araştırma sonuçlarına benzer özellik göstermektedir. ${ }^{2,20,21}$ Üniversite öğrencilerinde yapılan bazı araştırmalarda; uyku kalitesi ve öğrenim gördükleri sınıf arasında araştırma sonuçla- 
Tablo 2. Öğrenciler in temel özellikleri ile PUKİ puan ortalamalarının karşılaştırılması (Devam).

\begin{tabular}{|c|c|c|c|}
\hline \multicolumn{4}{|l|}{ İkametgâh ettiği yer } \\
\hline Ailemle evde & 132 & $6,51 \pm 2,48$ & \multirow{5}{*}{$\begin{array}{l}F=0,525 \\
p=0,717\end{array}$} \\
\hline Devlet yurdu & 107 & $6,31 \pm 2,65$ & \\
\hline Özel yurt & 25 & $5,72 \pm 2,44$ & \\
\hline Arkadaşımla evde & 12 & $6,33 \pm 2,46$ & \\
\hline Tek başına evde & 4 & $6,50 \pm 3,10$ & \\
\hline \multicolumn{4}{|c|}{ Part-time işte çalıșma durumu } \\
\hline Çalıșan & 10 & $7,10 \pm 3,54$ & \multirow{2}{*}{$\begin{array}{l}\mathrm{t}=0,935 \\
\mathrm{p}=0,350\end{array}$} \\
\hline Çalıșmayan & 270 & $6,33 \pm 2,50$ & \\
\hline \multicolumn{4}{|c|}{ Herhangi bir kronik hastalığı olma durumu } \\
\hline Evet, var & 30 & $6,46 \pm 3,65$ & \multirow{2}{*}{$\begin{array}{l}\mathrm{t}=0,241 \\
\mathrm{p}=0,810\end{array}$} \\
\hline Hayır, yok & 250 & $6,34 \pm 2,38$ & \\
\hline \multicolumn{4}{|l|}{ Sigara kullanma durumu } \\
\hline Evet, kullanıyor & 25 & $7,68 \pm 2,56$ & \multirow{2}{*}{$\begin{array}{l}\mathrm{t}=2,748 \\
\mathrm{p}=0,006\end{array}$} \\
\hline Hayır, kullanmıyor & 255 & $6,23 \pm 2,51$ & \\
\hline \multicolumn{4}{|l|}{ Alkol kullanma durumu } \\
\hline Evet, kullanıyor & 8 & $7,25 \pm 2,65$ & \multirow{2}{*}{$\begin{array}{l}\mathrm{t}=1,003 \\
\mathrm{p}=0,317\end{array}$} \\
\hline Hayır, kullanmıyor & 272 & $6,33 \pm 2,54$ & \\
\hline \multicolumn{4}{|c|}{ Uyumadan önce internet kullanma durumu } \\
\hline Evet, kullanıyor & 272 & $6,38 \pm 2,54$ & \multirow{2}{*}{$\begin{array}{l}\mathrm{t}=1,112 \\
\mathrm{p}=0,267\end{array}$} \\
\hline Hayır, kullanmıyor & 8 & $5,37 \pm 2,44$ & \\
\hline \multicolumn{4}{|c|}{ Yatmadan önce kafeinli içecek tüketimi durumu } \\
\hline Evet, tüketiyor & 105 & $7,16 \pm 2,59$ & \multirow{2}{*}{$\begin{array}{l}\mathrm{t}=4,201 \\
\mathrm{p}=0,000\end{array}$} \\
\hline Hayır, tüketmiyor & 175 & $5,88 \pm 2,39$ & \\
\hline \multicolumn{4}{|c|}{ Ders dinlerken uyuklama durumu } \\
\hline Evet, uyukluyor & 212 & $6,55 \pm 2,63$ & \multirow{2}{*}{$\begin{array}{l}\mathrm{t}=2,292 \\
\mathrm{p}=0,023\end{array}$} \\
\hline Hayır, uyuklamıyor & 68 & $6,36 \pm 2,54$ & \\
\hline
\end{tabular}

PUKİ: Pittsburgh Uyku Kalitesi İndeksi..

Tablo 3. Araştırmaya katılanların PUKİ puan ortalamaları ile akademik puan ortalamalarının karşılaştırılmasi.

\begin{tabular}{|l|l|l|}
\hline & $\mathbf{n}$ & Akademik Ortalama* \\
\hline $\begin{array}{l}\text { PUKİ Puan Ortalama- } \\
\text { sı }\end{array}$ & $\mathbf{2 8 0}$ & $\begin{array}{l}\mathbf{- 0 , 1 2 0 * *} \\
\mathbf{p}=\mathbf{0 , 0 4 4}\end{array}$ \\
\hline
\end{tabular}

*: Akademik ortalamalar araştırmaya katılanlar tarafından bildirilmiştir; **: Korelasyon katsayısı; PUKİ: Pittsburgh Uyku Kalitesi İndeksi.

rına benzer sonuçlar bulunmuştur. ${ }^{21,22}$ Araştırma sonucundan farklı olarak yapılan araştırmalarda uyku ile ilgili problemlerin üniversitenin ilk yıllarında ortaya çıktığı ve üniversiteye yeni başlayan öğrencilerin uyku kalitesinin daha kötü olduğu tespit edilmiştir. $^{20,23}$ Yapılan bu araştırmada üniversite birinci sınıfta okuyan öğrencilerin PUKİ puan ortalamas1 diğer sınıflarda okuyan öğrencilerin PUKİ puan ortalamasından yüksektir $(6,57 \pm 2,39)$. Birinci sinıfta okuyan öğrencilerin uyku kalitelerinin diğer sınıfta okuyan öğrencilerin uyku kalitelerine göre kötü olmasına rağmen, öğrencilerin öğrenim gördükleri sınıf ile uyku kalitesi arasında istatistiksel açıdan anlamlı bir fark bulunamamıştır. Üniversite öğrencilerine yönelik yapılan bir araştırmada ekonomik durumu iyi olanların uyku kalitesinin daha kötü olduğu belirtilmiştir. ${ }^{7}$ Ülkemizde hemşirelik ve ebelik ögrencilerinde yapılan bir araştırmada ise ekonomik durum ile uyku kalitesinin arasında ilişki bulunamamıştır. ${ }^{20}$ Literatür incelendiğinde bu araştırma sonu- cundan farklı olarak ikamet yeri yurt olan öğrencilerin uyku kalitelerinin daha kötü olduğu tespit edilmiştir. ${ }^{2,20}$ Yurtta kalan öğrencilerin daha kalabalık odalarda kaldıkları için uyku kalitelerinin diğer öğrencilerden daha kötü olacağı düşünülebilir. Çevresel değişkenlerin içerisinde kalabalık ortamda kalma dışında; havalandırma, ortam 1sısı, aydınlatma duru$\mathrm{mu}$, yatak konfor durumu da değerlendirilmelidir. Yapılan bu araştırmada sonucun farklı olması; diğer illere göre Konya il merkezindeki yurtların, fiziki şartlarının ev ortamını aratmayacak konforda, ulaşım ve yemek imkanlarının ise diğer illere göre oldukça iyi olmasından kaynaklanmış olabilir. Literatüre bakıldığında üniversite öğrencilerinin uyku kalitesi üzerine yapılan araştırmalarda da öğrencilerin part time çalışma durumu ve kronik hastalığa sahip olma durumu ile uyku kalitesi arasındaki ilişki araştırma sonuçlarına paralellik göstermektedir. ${ }^{2}$ Araştırma sonucundan farklı olarak yapılan benzer araştırmalarda kronik hastalığa sahip olanların sahip olmayan- 
lara göre uyku kalitesinin daha kötü olduğu tespit edilmiştir. ${ }^{7,20} \mathrm{Bu}$ farklılık; araştırmadaki örneklem grubunun uyku kalitesini olumsuz yönde etkileyecek ciddi bir kronik hastalığa sahip olmamasından kaynaklanmış olabilir.

Araştırmada katılımcıların sigara kullanma durumuna göre uyku kalitesi incelendiğinde sigara kullanan öğrencilerin uyku kalitesinin sigara kullanmayan öğrencilere göre daha kötü olduğu tespit edilmiştir ( $\mathrm{p}<0,05$; Tablo 2). Literatürde yapılan araştırmalar da bu araştırma sonucu ile uyumludur. ${ }^{2,7,22,23}$ Sigarada bulunan nikotinin uyarıcı etkisi ile solunum sorunları ortaya çıkabilmektedir. ${ }^{24} \mathrm{Bu}$ durum; gece uykularının bölünmesine, uykuya dalmada güçlüklerin yaşanmasına yol açarak uyku kalitesinin azalmasina neden olabilir. Alkol kullanma durumu da sigara gibi riskli bir davranış olmasına rağmen ve uyku kalitesini de etkileyen olumsuz davranışlar arasında olmasına rağmen yapılan araştırmada alkol kullanma durumu ile uyku kalitesi arasında anlamlı bir ilişki bulunmamıştır ( $>00,05$; Tablo 2$)$. Literatürde yapılan araştırmalar alkol kullananların uyku kalitesinin daha kötü olduğunu belirtmektedir. ${ }^{17,20}$ Yapılan bazı araştırmalar ise araştırma sonucunu destekler nitelikte olup alkol kullanmanın uyku kalitesini etkilemediğini bildirmektedir. ${ }^{2,23}$ Küreselleşmenin de etkisi ile son zamanlarda internet kullanımının artmasına bağ11 olarak uyku kalitesinin bu durumdan nasil etkilendiği incelenmektedir. ${ }^{9}$ Yapılan araştırmada uyumadan önce internet kullanma durumu ile uyku kalitesi arasında anlamlı bir ilişki bulunmamıştır ( $p>0,05$; Tablo 2). Literatürde yapılan araştırmalarda uyumadan önce 2 saatten fazla internet kullanımının uyku kalitesini olumsuz yönde etkilediği belirtilmektedir. ${ }^{7}$ Yapılan bir araştırmada uyumadan önce son bir saat ekran kullanımının uyku kalitesini etkilemediği fakat uyumadan önce yatak içi ekran kullanımının uyku kalitesini olumsuz yönde etkilediği tespit edilmiştir. ${ }^{2}$ Yapılan araştırmada uyumadan önce internet kullanım saatleri kategorize edilmemiştir bu nedenle internet kullanımının uyku kalitesine etkisinin incelenmesinde uyumadan önce internet kulanım saatinin göz ardı edilmemesi gereken bir durum olduğu düşünülmektedir. Uyku kalitesini etkileyen bir diğer faktör ise yatmadan önce kafeinli içecek tüketim durumudur. Yapılan araştırmada yatmadan önce kafeinli içecek tüketenlerin uyku kalitesinin daha kötü olduğu tespit edilmiştir ( $<<0,05$; Tablo 2). Literatürde yapılan araştırmalar araştırma sonucuna paralellik göstermektedir. ${ }^{21,25}$ Uyku dönemini hızlı göz hareketlerinin eşlik etmediği NREM ve hızlı göz hareketlerinin eşlik ettiği REM oluşturmaktadır. ${ }^{26}$ Kafein, REM uykusunun başlangıcında değişikliğe yol açar ve NREM uykusunu etkiler. Bu durum kişilerin uykuya dalmasında problem oluşturarak toplam uyku süresini kısaltmaktadır. ${ }^{26,27}$ Yapılan bir araştırmada; yatmadan önce fazla miktarda tüketilen kafe- inli içeceklerin uykuya dalma süresini normale göre dört kat uzattığ 1 belirtilmiştir. Araştırmada katılımcıların ders dinlerken uyuklama durumu ile uyku kalitesi incelendiğinde istatistiksel açıdan anlamlı bir fark bulunmuştur ( $\mathrm{p}<0,05$; Tablo 2). Ders dinlerken uyuklayan öğrencilerin uyku kalitesinin daha kötü olduğu belirlenmiştir. Kötü uyku kalitesinin ve gündüz uykululuğunun; kardiyovasküler sorunlara yol açtığı, motorlu taşıt kazalarına neden olduğu ve akademik başarıyı da olumsuz yönde etkilediği bilinmektedir. Derste uyuklamak öğrencilerin akademik başarılarını ve derse olan motivasyonlarını önemli ölçüde olumsuz yönde etkileyebilir. ${ }^{28}$ Araştırmada katılımcıların akademik puan ortalaması ile uyku kalitesi puanı arasındaki ilişki incelendiğinde aralarında negatif yönlü bir ilişki olduğu tespit edilmiştir. ( $<<0,05$; Tablo 3). Araştırmada kötü uyku kalitesine sahip olanların akademik başarısı daha düşüktür. Kötü uyku kalitesine sahip olmak bireylerde konsantrasyon eksikliği oluşturmakta ve gün içerisinde çalışmalarına engel olmaktadır. Bu durum da akademik performansı olumsuz yönde etkilemektedir. ${ }^{29}$ Literatürde uyku kalitesi ve akademik başarı arasındaki ilişkileri inceleyen az sayıda araştırma bulunmaktadır. Yapılan bazı araştırmalar araştırma sonucuna paralellik göstermektedir. ${ }^{7,28}$ Yapılan araştırmada akademik performans ile PUKİ puan ortalamaS1 arasında negatif yönlü zayıf bir ilişki tespit edilmiştir $(r<0,20$; $p<0,05)$. Bu durum akademik başarıy1 uyku haricinde diğer faktörlerin de etkilemesinden kaynaklanmış olabilir. Yapılan araştırmalarda kötü uyku kalitesinin akademik başarıyı etkileme nedenleri; dikkat dağınıklığı, uykululuk, isteksizlik, hafıza sorunlarıdır. ${ }^{28}$ Yapılan bir diğer araştırmada ise kötü uyku kalitesinin akademik başarıyı etkileme nedenleri; üniversiteye uyum sağlama aşaması olmas1, sigara ve alkol kullanımı, kalınan yer, uyumadan önce internet kullanımı, kronik hastalık veya ruhsal hastalığın olması olarak tespit edilmiştir. ${ }^{7}$ Yapılan araştırmada ise kötü uyku kalitesinin akademik başarıyı etkileme nedenleri; sigara kullanım durumu, yatmadan önce kafeinli içecek tüketme durumu ve ders dinlerken uyuklama durumu olarak belirlenmiştir.

Araştırma sonucunda hemşirelik fakültesinde öğrenim gören öğrencilerin genel olarak uyku kalitelerinin kötü olduğu tespit edilmiştir. Araştırmaya kat1lan öğrencilerden uyku kalitesi kötü olanların akademik puan ortalamaları daha düşüktür. Uyku, öğrencilerin not ortalamasına etki eden faktörler arasındadır. Öğrencilerin akademik başarılarının iyi olması, donanımlı mezunların yetiştirilmesinde ve meslek yaşamlarında sorumlu lider ya da insan gücü olarak görülmelerinde önemli rol oynamaktadır. Bu yüzden gelecekte profesyonel sağlık hizmetlerinin sunumunda yer alacak olan hemşirelik öğrencilerinin uyku kalitesinin önemi konusunda bilinçlendirilmesi için 
danışmanlık hizmetleri verilebilir. Hemşirelik öğrencilerinde uyku kalitesinin iyileştirilmesine yönelik araştırmaların yapılması ve ileride yapılacak benzer araştırmaların daha geniş örneklemler ile tekrarlanması önerilebilir.

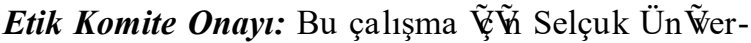
sitesi Sağlık Bilimleri Fakültesi Girişimsel Olmayan Araştırmalar Etik Kurulu'ndan etik kurul izni alınmıştır (Tarih:25.12.2019, karar no: 2019/14564).

Çıkar Çatışması: Yazarlar çıkar çatışması bṼd Ṽmemişlerdir.

Yazar Katkıları: F $\tilde{\mathrm{K}} \tilde{\mathrm{V}}$ - GE, BA; Veri Toplanması ve/veya İşleme - GE; Analiz ve/veya Yorum - GE, BA; Yazıyı yazan - GE, BA.

Hakem Değerlendirmesi: Dış bağımsız.

Teşekkür: Yazarlar, çalışmaya katılan hemş $\tilde{Y} e l \tilde{k}$ öğrencilerine teşekkür eder.

\section{KAYNAKLAR}

1. Troynikov O, Watson CG, Nawaz N. Sleep environments and sleep physiology: A review. J Therm Biol. 2018;78:192-203.

2. Ergin A, Acar GA, Bekar T. Sağlıkla ilgili eğitim veren fakültelerdeki öğrencilerin uyku kalitesinin belirlenmesi. Pamukkale Tip Dergisi. 2018;11 (3):347-354.

3. Peltzer K, Pengpid S. Nocturnal sleep problems among university students from 26 countries. Sleep and Breathing. 2015;19(2):499-508.

4. Jain V, Tomar R, Jha J, Pareek A, Ratan Y, Paliwal N. Sleep quality and sleep associated problems in female pharmacy students. Chronicles of Young Scientists. 2013;4(2):138-143.

5. Beauvais AM, Stewart JG, DeNisco S, Beauvais JE. Factors related to academic success among nursing students: A descriptive correlational research study. Nurse Education Today. 2014;34 (6):918-923.

6. Mirghani HO, Mohammed OS, Almurtadha YM, Ahmed MS. Good sleep quality is associated with better academic performance among Sudanese medical students. BMC Research Notes. 2015;8 (1):706-710.

7. Yoldaş G. Üniversite öğrencilerinin sağlıklı yaşam biçimi davranışları, uyku kalitesi ve akademik başarıları arasındaki ilişki. Gazi Üniversitesi, Hemşirelik Anabililm Dalı, Yüksek Lisans Tezi, Ankara, Türkiye; 2017.

8. Nihayah M, Ismarulyusda I, Syarif HL, Zakiah MSN, Baharudin O, Fadzil MH. Sleeping hours and academic achievements: a study among biomedical science students. Procedia - Social and Behavioral Sciences. 2011;18:617-621.

9. Ghosh T, Sarkar D, Sarkar K, Dalai C, Ghosal A. A study on smartphone addiction and its effects on sleep quality among nursing students in a mu- nicipality town of West Bengal. Journal of Family Medicine and Primary Care. 2021;10(1):378-386.

10. Aysan E, Karaköse $\mathrm{S}$, Zaybak A, İsmailoğlu EG. Üniversite öğrencilerinde uyku kalitesi ve etkileyen faktörler. Dokuz Eylül Üniversitesi Hemşirelik Fakültesi Elektronik Dergisi. 2014;7(3):193198.

11. Mayda AS, Kasap H, Yildırım C, et al. 4-5-6. sınıf tıp fakültesi öğrencilerinde uyku bozukluğu sıklığı. Düzce Üniversitesi Sağlık Bilimleri Enstitüsü Dergisi. 2012;2(2):8-11.

12. Lemma S, Gelaye B, Berhane Y, Worku A, Williams MA. Sleep quality and its psychological correlates among university students in Ethiopia: a cross-sectional study. BMC Psychiatry. 2012;12 (1):237-243.

13. Mushtaq I, Khan SN. Factors affecting students' academic performance. Journal of management and business research. 2012;12(9):16-22.

14. Yazıcıoğlu Y, Erdoğan S. Spss uygulamalı bilimsel araştırma yöntemleri. Detay Yayıncılık, Ankara/Türkiye. 2004.

15. Sarı ÖY, Üner S, Büyükakkuş B, Bostancı EÖ, Çeliksöz AH, Budak M. Bir üniversitenin yurtta kalan öğrencilerinde uyku kalitesi ve etkileyen bazı faktörler. TAF Preventive Medicine Bulletin. 2015;14(2):93-100.

16. Saygılı S, Akıncı AÇ, Arıkan H, Dereli E. Üniversite öğrencilerinde uyku kalitesi ve yorgunluk. Ejovoc (Electronic Journal of Vocational Colleges). 2011;1(1):88-94.

17. Uysal H, Ayvaz MY, Oruçoglu HB, Say E. Universite ögrencilerinin beslenme durumu ve uyku kalitesinin değerlendirilmesi. Journal of Turkish Sleep Medicine. 2018;5(2):31-40.

18. Buysse DJ, Reynolds CF, Monk TH, Berman SR, Kupfer DJ. The Pittsburgh sleep quality index: A new instrument for psychiatric practice and research. Psychiatry Research. 1989;28(2):193-213.

19. Akargun M, Kara H, Anlar O. Pittsburgh uyku kalitesi indeksinin geçerliligi ve güvenirligi. Turk Psikiyatri Dergisi. 1996;7(2):107-115.

20. Ergün S, Duran S, Gültekin M, Yanar S. Sağlık yüksekokulu öğrencilerinde uyku alışkanlığı ve kalitesini etkileyen faktörlerin değerlendirilmesi. TJFMPC. 2017;11(3):186-193.

21. Yilmaz D, Tanrikulu F, Dikmen Y. Research on Sleep Quality and the Factors Affecting the Sleep Quality of the Nursing Students. Curr Health Sci J. 2017;43(1):20-24.

22. Şalva T, Güllüoğlu M, Kaya M, Özdemir K. Maltepe Üniversitesi tıp fakültesi 1. ve 6. sınıf öğrencilerinde uyku kalitesi ve etkileyen faktörler. Maltepe Tip Dergisi. 2020;12(2):27-33.

23. Karatay G, Gürarslan Baş N, Aldemir H, Akay M, Bayır M, Onaylı E. Hemşirelik bölümü öğrencilerinin uyku alışkanları ve etkileyen etmenlerin 
incelenmesi. Sağlık Bilimleri ve Meslekleri Dergisi. 2016;3(1):16-22.

24. Herman M, Tarran R. E-cigarettes, nicotine, the lung and the brain: multi-level cascading pathophysiology. J Physiol. 2020;598(22):50635071. doi:10.1113/jp278388

25. Suna G. Üniversite öğrencilerinde uyku kalitesi ve yeme davranışının değerlendirilmesi. Hacettepe Üniversitesi, Beslenme ve Diyetetik Ana Bilim Dalı, Yüksek Lisans Tezi, Ankara, Türkiye; 2016.

26. Özpalas B, Özer EA. Effects of caffeine on human health. Nevşehir Bilim ve Teknoloji Dergisi. 2017;6:297-305.

27. O'Callaghan F, Muurlink O, Reid N. Effects of caffeine on sleep quality and daytime functioning. Risk Manag Healthc Policy. 2018;11:263-271.

28. Okano K, Kaczmarzyk JR, Dave N, Gabrieli JDE, Grossman JC. Sleep quality, duration, and consistency are associated with better academic performance in college students. npj Science of Learning. 2019;4(1):16.

29. Prichard JR. Sleep Predicts Collegiate Academic Performance: Implications for Equity in Student Retention and Success. Sleep Med Clin. 2020;15 (1):59-69. 